\title{
Advantages and Disadvantages of Green Technology; Goals, Challenges and Strengths
}

\author{
Abolfazl Iravani \\ Master of Agricultural \\ Engineering \\ Azad University of Birjand \\ Birjand, Iran
}

\author{
Mohammad Hasan akbari \\ Master of Public \\ Administration (Governmental \\ Management) \\ Farabi Campus, University of \\ Tehran \\ Birjand, Iran
}

\author{
Mahmood Zohoori \\ Master of Environmental \\ Management \\ Putra University of Malaysia \\ Birjand, Iran
}

\begin{abstract}
The concept of green processes and technologies is the processes and technologies which are environmentally friendly, improved and utilized in such a way so that it doesn't disorganize the environment and conserve natural resources. Some people refer green technology as environmental technology and clean technology. The existing expectation is that this field will bring novelty and innovation changes in diurnal life of same magnitude of information technology. Besides, today due to the importance of this technologies, most of the governments takes initiatives to promote it. Therefore, governments recommended many financial incentives which generate electricity from renewable resources. The goals of green technologies are as follow: to meet the needs of society in the way without depleting or damaging natural resources on earth which is the major target of green technologies. The concept is to make products which can be fully reclaimed or reused. Furthermore, by changing patterns of production and consumption, steps are being taken into account to diminish waste and pollution as one of the most indispensable aims of green technologies. Many companies have committed for establishing manufacturing practices and business regarding green technologies. Besides, this kind of technology implies to a system which utilizes innovative techniques to create environmental friendly products. Predominantly, it contains the various everyday cleaning products, waste, inventions, energy sources, clothing and host of others. Going green or using technologies which are environmental friendly is amongst the many methods which countries are looking in order to spur economic growth and develop the lives of its citizens. Green processes and technologies use renewable and natural resources which never depletes. Besides, green technology utilizes innovative and new techniques in terms of energy generation. Furthermore, green nanotechnology which utilizes green chemistry and green engineering is one of the newest in green technologies. One of the most important factors for pollution of environment is the disposal of waste which green technology has the answers to it as well. This kind of technology can easily alter the waste pattern and production in a way which it does not deteriorate the earth and people can go green. Furthermore, among the conceivable areas where these creations and growth are expected to come from involve organic farming, green energy, green building construction, eco-textiles, and manufacturing of relevant products and materials to support green business. Because it is new to the industries. Besides, it is also expected to absorb new clients who will see too many advantages of using green technologies in their places and others. Therefore, the main goal is to utilize green technology which has no adverse effects on the planet. Nowadays there are huge concerns regarding environmental pollution which bring attentions on the utilization of green products and processes. There are a great amount of researchers who have been conducted and are being conducted in different industries with various scopes in this term. However, the essential point is whether green technology are able to adapt in various industries. Certainly, one of the major problems in the globe is pollution which has created a huge concern in relation to the future human life. Therefore, this paper concentrates on the advantages and disadvantages of green technology.
\end{abstract}

Keywords: Green technology, Environmental pollution, Renewable energy, green chemistry, eco-friendly technology, organic farming

\section{INTRODUCTION}

Nowadays industries consume more energy than what it is essential, so it leads to more pollution. That's why it is necessary to create a managerial system based on green processes and products to decrease the pollutions. Besides, the opportunities are provided in green technology. Governments, companies and industries all around the globe seek have been seeking for methods and techniques to diminish the waste, because the earth's environment is not in a proper situation today in terms of pollution for instance: water contamination, global warming and forest disappearing which are main difficulties for environment. However, in roofed environment such as offices with mechanical ventilation, but without circulation, tools like computers may lead sensory pollution loads (Al-Ali et al., 
2010), (Zohoori et al., 2016). In point of fact, the personal computers (PCs) considered as a potent indoor pollution sources. Furthermore, when PCs are services for every three months, sensory pollution load of every singular one is 3.4 Olfactus (olf) (Bakó-Biró et al., 2004), (Zohoori et al., 2016).

Chemical analysis detects the pollutants emitted by PCs. The most remarkable chemicals involve phenol, toluene, 2- ethylhexanol, formaldehyde, and styrene (Al-Ali et al., 2010). Therefore, these types of pollutants include an indespisable adverse effect on the air quality, not only in the offices but also in many spaces like houses. In addition, (National Public Radio) NPR reported by Chris Arnold in 2004 from Environmental Protection Agency (EPA) officials said: Computers and their monitors in the United States have the responsibility for the unessential creation of millions of tons of greenhouse gases per year (Ravali et al., 2011). Besides, as the whole globe have been talking about going green, everybody can chip-in his/her bit for saving environment, energy and money. Commonly, PCs and other IT equipment consume a great amount of electricity and have high carbon emission levels. Moreover, the utilization of green technology are especially designed to minimize power consumption (Zohoori et al., 2016).

As the name implies green technology is one which has a green purpose. $\quad$ Furthermore, green inventions are environmentally friendly inventions which often include energy efficiency, recycling health and safety concerns, renewables and more. The world has its fixed amount of natural resources which some of them are already depleted or destroyed. For instance: electronics and household batteries often involve hazardous chemicals which can contaminate the groundwater after disposal, polluting soil and water with chemicals which cannot be eliminated from the potable water supply and food crops grown on polluted soil. Moreover, the risks on human health are tremendous. So, every investor needs to think green and know that green inventions and clean technology are such proper business as well as its growing markets with growing benefits. Besides, from the point of view of the consumers it should be known that purchasing green inventions can diminish their energy bills as well as safer and healthier products (Zohoori et al., 2016).

\section{Literature review}

\subsection{Definition of Technology}

The word technology is being used to refer to a collection of skills, methods, processes and techniques utilized in the production of goods and services or in achieving of the goals like scientific investigation. Besides, technology is the knowledge of how to combine the resources to produce the desirable products, to solve the difficulties, fulfill the needs, satisfied wants. 
Furthermore, it involves technical methods, proficiency, techniques, tools, raw materials and etc, or it can be embedded in machines, computers, devices and factories, which can be operated by peoples without detailed knowledge of the working of such things. Currently, the state of technology is the application of science, arts and math for the profit of life as it is wellknown technology (Monu Bhardwaj et al., 2015).

\subsection{What Is Green Technology?}

Clean or green technology is the improvement and application of equipment, systems and products utilized to save the natural environment and resources which minimize and decrease the adverse effect of human activities (Monu Bhardwaj et al., 2015). Green technology satisfy the following criteria:

a) It minimizes the deterioration of the environment;

b) It lowers greenhouse gases (GHG) emission to zero as well as its utilization is safe and finally it enhances healthy and improved environment for all forms of life.

c) It saves the use of natural resources and energy.

d) It enhances the utilization of renewables.

\subsection{Categories of Green technology}

Green technology covers a vast area of production and consumption technologies. The adoption and utilization of green technology include the exploitation of environmental technology for monitoring and evaluating, pollution prevention, control, remediation and restoration. Furthermore, monitoring and evaluating of technology are used to measure and track the condition of the environment, involving the release of natural or anthropogenic materials of a detrimental nature.

Prevention technologies refrain the production of hazardous materials or change human activities in the ways which minimize damages to the environment. Moreover, it encompasses product substitution or redesign of a whole production process rather that utilizing new pieces of equipment. Besides, control technologies render hazardous materials harmless before entering the environment. Furthermore, remediation and restoration technologies embody techniques and methods designed to develop the condition of ecosystems, degraded through naturally induced or anthropogenic effects (Sanjukta Banerjee et al., 2014).

One of the most famous examples of green technology is solar cell. A solar cell directly transforms the energy into light or electricity through the process of photovoltaic. Besides, generating electricity from solar energy means reduction in consumption of fossil fuels and greenhouse gases emissions and less pollution. Moreover, another ordinary invention which can be seen 
green is the reusable of water bottle. Naturally, drinking lots of water is healthful, so reduction in the amount of plastic waste is excellent for the environment and wildlife. Therefore, reusable water bottles which can be refilled are health-promoting, ecofriendly, and as well as green (Sanjukta Banerjee et al., 2014).

\subsubsection{Energy}

Perhaps development of alternative fuels, new means of generating energy and energy efficiency are the most instant matter for green technology. In addition, renewable energy involves efficiency technology, water management and water purification, recycling technology, sewage treatment and solid waste management. In accordance to the IEA, World Energy Outlook, the world's first energy supply has ascended by 58 percent in 25 years, from roughly 7.2 billion TOE (tons of oil equivalent) in 1980 to around 11.4 billion TOE in 2005. Table 1 demonstrates the perspective of world energy demand (Source: IEA World Energy; Outlook 2007, 2008).

Table 1, Perspective of World Energy Demand

\begin{tabular}{|c|c|c|c|c|c|}
\hline \multirow{2}{*}{ Item / Y } & \multicolumn{4}{|c|}{ Energy Demand (M ton) } \\
\cline { 2 - 6 } & 1980 & 2000 & 2005 & 2015 \\
\hline Total primary energy demand & 7,223 & 10,034 & 11,429 & 14,121 & 17,014 \\
\hline Petroleum oil & 3,107 & 3,649 & 4,000 & 4,525 & 2,1030 \\
\hline Transport & 1,245 & 1,936 & 2,011 & 2,637 \\
\hline Petroleum & 1,187 & 1,844 & 1,895 & 2,450 \\
\hline Biofuels & 2 & 10 & 19 & 74 \\
\hline Other fuels & 57 & 82 & 96 & 118 \\
\hline
\end{tabular}


- Improve asset value and benefits

Green building or sustainable design, is the practice of rising the efficiency which buildings and their sites utilize energy, water and materials and their decreasing impacts on human health and the environment for the whole lifecycle of a building. The concepts of green building expand beyond the walls of buildings and involve site planning, community and land-use planning issues as well. The rise of the communities has a huge impact on natural environment. Furthermore, the manufacturing, design, construction and operation of the buildings are responsible for the consumption of natural resources (http://www.wncgbc.org/about/impor tance-of-green-building).

Besides, green building contains everything from the choice of materials to where a building is located for instance: sustainable building material and building performance technology (Sanjukta Banerjee et al., 2014).

\subsubsection{Environmental profits of green building:}

- Improve and protect biodiversity and ecosystems

- Enhance air and water quality

- Diminish waste streams

- Conserve and retrieve natural resources

\subsubsection{Economic benefits of green building:}

- Decline operation costs

- Enhance occupant productivity
- Optimize the economic performance of lifecycle

\subsubsection{Social benefits of green building:}

- Boost occupant wellness and easement

- Elevate indoor air quality

- Minimize strain on local utility infrastructure

- Develop whole quality of life

\subsubsection{Environmentally preferred} purchasing

Innovation contains the survey for products in which contents and techniques of production have the slightest possible effect on the environment, and mandates which these be the preferred products for government purchasing (Sanjukta Banerjee et al., 2014).

Besides, in many areas like North America, green technology is becoming the quickest growing segment of the economy. In addition, the field of green technology includes many various products and services within different industries such as transportation, management of waste, agriculture, energy and water supply. However, all of these technologies have something in common and that is implementation with a diversity of industries, which 
not only optimize the operational efficiency but also reduce the negative impact regarding environment. In fact, green technology is the best solution when it comes to sustaining the business segment. Here are four elementary business goals of green technology which assist different organizations to maximize their operations

(http://www.powerhousegrowers.co

$\mathrm{m} / 4$-business-goals-of-green technology/).

\subsubsection{Business goals of green technology}

\subsection{Sustainability Goals}

The systematic shift from short-term gain which deteriorates natural resources to the long-term prosperity of future generations. This kind of shift is mindset for a lot of organizations.

\subsection{Product Life Cycle Goals}

Especially depending to manufacturers, performing life cycle evaluations finishes the "cradle to grave" cycle of production. Besides, products can be manufactured utilizing a life cycle evaluation to ascertain cradle to cradle cycles whereby products can be reused at the end of their life.

\subsection{Product Efficiency Goals}

Decreasing the pollution, waste and resources consumption which takes place during the manufacturing process at many various stages. This may contain post-production efficiency for instance diminishing impacts of shipping as well.

\subsection{Closed-Loop Innovation}

The whole technology controlled "smart systems" monitor consumption of resources and management of waste, while accounting for metrics which otherwise would never have been contained.

\subsubsection{Green-chemistry}

Green chemistry is called sustainable chemistry as well. Besides, it is a philosophy of chemical research and engineering which encourages the design of products and processes which minimize the utilization and generation of hazardous materials. Moreover, in 1990 the Pollution Prevention Act was passed in United States. In addition, this act assisted to create a modus operandi for dealing with pollution in an original and innovative way. Besides, it aims to refrain difficulties prior they take place. Moreover, green chemistry applies to organic chemistry, inorganic chemistry, biochemistry, analytical chemistry and even 
physical chemistry. (Ghanshyam Das Soni 2015).

\subsubsection{Green-nanotechnology}

Nanotechnology includes the manipulation of matters at the scale of the nanometer which is one billionth of a meter. There are some researchers who believe that mastery of this issue is forthcoming which will convert the method which everything in the world is manufactured.

"Greennanotechnology" is the application of green engineering and chemistry to this field (Ghanshyam Das Soni 2015).

\section{Significance Green Technology}

Green technology is an environmentally friendly technology which is improved and utilized in a way which conserves the environment and protects natural resources. The significance of green technology can't be ignored especially the part pertains to humanity. Besides, going green is the only option to help humanity come out of the current strict situation. Therefore, before the things turn for the worst, it is indispensable to realize the significance of green technology to solve the problems. (www.ajcebeats.com/theimportance-of-green-technology/).

\section{Goals of Green Technology}

The aims of green technology are myriads. The major objective of green technology is to meet the needs of society in ways without damaging or depleting natural resources on the planet. In addition, the opinion is to meet the present needs without making any compromise. Besides, it is required to find the right destination to get all about the goals of this kind of technology. The concentration of green technology is to make products which can be fully reclaimed or reused. In addition, steps are being taken to decrease wastes and pollution as one of the most indispensable aims of green technology via changing patterns of production and consumption. Moreover, it is necessary to improve alternative technologies to hamper any further damage to environment and health. The solution is precipitation in the implementation of these kind of technologies to benefit and protect the earth. The important goals of green technology introduce sustainable living, develop renewable energy, decrease 
production of waste, conserve the

utilization of natural resources,

creation of products which are

reusable and recyclable, and

inventing alternatives to the practices

which adversely affect the human

and environment (Monu Bhardwaj et

al., 2015).

\section{From Sustainability to}

\section{Greenability}

Sustainability is commonly considered from three dimensions including the social, the economic and the environmental which is provided by the United Nation (Coral Calero et al., 2015), IEEE (2014). As shown in figure 1 , the third dimension is called green.

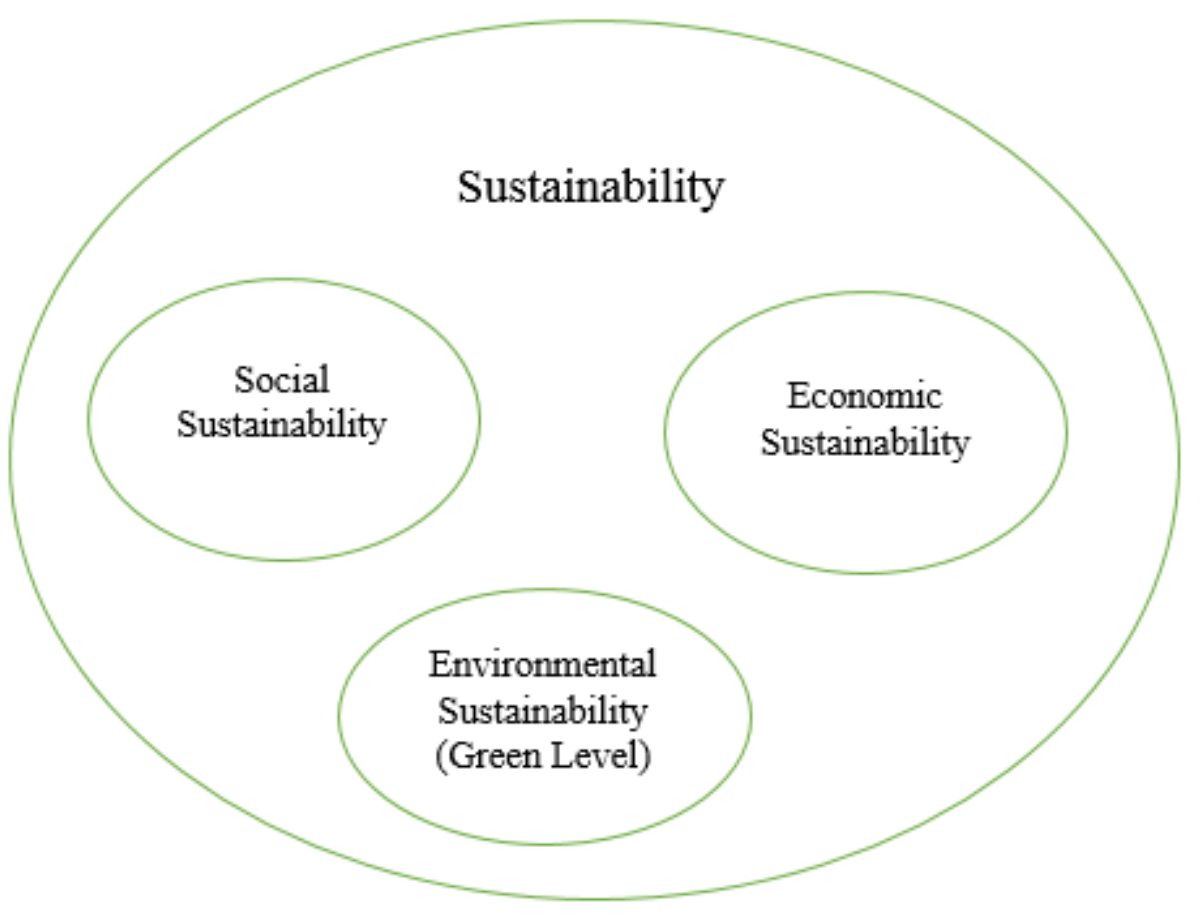




\section{Challenges to Green Technology Adoption}

In general, green technology is more expensive than the technology it aims to sub, because it accounts for the environmental costs which hare externalized in many conventional production processes. This is a novel technology and there is many things in it which is unknown. In addition, the associated improvement and training costs make it even more costly in comparison with other established technologies. The perceived profits regarding this technology are also pertain to other factors for instance supporting infrastructure, technology readiness, human resource capabilities and geographic elements. Adoption and circulation of these technologies can be limited by a number of other obstacles. Some may be institutional like the lack of an appropriate regulatory framework, and others can be technological, financial, political, cultural or legal in nature. Besides, from company's view, the barriers to adopting green technology are high implementing costs, lack of data and information, no or lack of alternative chemical or raw material inputs, uncertainty regarding performance impacts, lack of human resources and finally, lack of skilled personnel. In addition, overcoming these barriers is a complicated process. Promoting green growth needs

$\begin{aligned} & \text { identifying and removing } \\ & \text { obstacles which prevent the }\end{aligned}$ large-
scale dissemination of
technology to improve

\section{Strengths from adopting green technology}

- Ability to meet rigid product specifications in foreign markets: Manufacturers in developing countries generally require to meet more stringent environmental specifications and requirements to export their commodities to developed and industrialized countries and vice versa. The adoption of green technology may help exporting companies to achieve advantage and market share over competitors.

- Rebate of input costs: Green technology can develop production efficiency through the reduction for input costs, energy costs and maintenance and operating costs which can develop a company's competitive position

- Environmental image: adoption of green technology can enhance a company's environmental reputation which is essential if other rivals and consumers are becoming more environmentally conscious.

- Ability to meet more stringent environmental regulations in the future: companies which invest in green technology are more likely to be better equipped and ready for rigid environmental regulations as well as commodity specifications 
which are expected to be imposed on them in the future.

\section{Advantages of Green Processes and Technology}

1. Does not release anything detrimental into atmosphere

2. Bring economic profits to certain areas

\section{Need less maintenance}

4. It is renewable which means will never run out

5. Slow the impacts of global warming by reducing $\mathrm{CO}_{2}$ emissions

The advantage of using green energy sources is that it must be clean therefore there is no discharge or damage into the environment or atmosphere. Besides, it is also replenishable in contrast to oil. In addition, green energy facilities are difficult on the pocketbook to build, it demands a lesser amount of upkeep thus it lacks to spend some huge cash to work it. Moreover, this may also create economic advantages to some particular areas and even develop tourism industry. Even while these seem excellent, there are a few who believe there exists profits to use such technology.

Establishing these facilities additionally needs plenty of land so we might have to cut on farmland which explains what many are worried about if more wind generators have to be set up. A second negative aspect is the fact many of the green energy sources cannot really be installed in specific places of the earth. As an example, wave energy can only be made use of if the waves from the sea attain at the least 16 feet. The utilization of geothermal energy only works in geologically unstable areas of the planet. But if we look at these kinds of arguments, areas that can't utilize one method of green energy source could be replaced for another.

If wind generators demand more room or space, they could be set up in the proximity of the coastline instead of positioning these on land. A study reveals you could get more electric power while these happen to be in the sea. As the weather is something we are not able to regulate, it is far from every day that there's a weather disruption so this too shall pass. If solar energy is being utilized and the sun is covered, the emergency generators will be stimulated and utilize up the power that was saved. Presently there exist ways around the misunderstandings put by a number of people which discourage the usage of green energy sources.

In truth, research is constant to try to use other means to generate the electrical power we need. A good example of this is known as ocean thermal energy. Energy is created by harnessing the diverse temperatures within the water. It is now being employed on a small scale both in Japan and Hawaii. In America, only $7 \%$ of green energy sources are used across the country. This was much higher 11 years ago and if we don't are limited to the money necessary 
for oil or even reduce our dependency on it, we must invest more in this clean energy. We can get it from green energy sources such as biomass, biodiesel, geothermal, solar, water and the wind. These are things just about everyone has around us and all it takes is for another person to harness it as a substitute for depending on traditional nonrenewable means to turn out energy (Sanjukta Banerjee et al., 2014).

\section{Disadvantages of Green Processes and Technology}

Green processes and technology refers to making efforts to improve energy efficiency or reduce the pollution produced by your home, business and general living habits. The main purpose of this kind of processes and technology is to reduce the potential negative impact that energy consumption and pollution can have on the environment. While environmentally friendly living is a positive ideal, there are several possible disadvantages of Green processes and technology such as: high implementing costs, lack of information, no known alternative chemical or raw material inputs, no known alternative process technology, uncertainty about performance impacts, and lack of human resources and skills (Recent Research in Science and Technology 2014, 6(1): 97-100 ISSN: 2076-5061 Available Online: http://recentscience.com).

\subsection{Initial Costs}

Perhaps the greatest disadvantage of going green is that it often requires a large initial cost. For example, installing a new roof or new insulation to keep heat from escaping your home would be considered a green home improvement, but it would cost a large sum of money to get the work done. Similarly, buying a hybrid vehicle that gets good gas mileage can reduce energy consumption, but hybrid vehicles often cost many thousands of dollars more than similar vehicles without hybrid technology. Upfront costs present a large deterrent to going green.

\subsection{Inadequate Savings}

The aim of going green in many cases, such as building an energyefficient home or purchasing a hybrid vehicle, is to reduce environmental impact while saving money in the long term. Green buildings and vehicles tend to use less energy, so initial costs can often be recouped over time through energy savings. The problem is that the savings generated by going green are often less than expected; they do not make up for the initial cost quickly enough to make them economically viable.

\subsection{Competition}

In the business world, going green can be an attractive goal to gain goodwill and consumer support, but unless green improvements are economically viable, it can put a 
business at a competitive disadvantage. For instance, if one company decides to adhere to strict, self-imposed pollution standards which require the installation of new technology and workers, while another sets loose standards, the second company will be at an advantage since they will have lower production costs. Even if national standards were imposed to force businesses to go green, this could put them at a competitive disadvantage with respect to foreign companies.

\subsection{Marginal Impact}

While going green is focused on reducing harm to the environment, the impact that any specific individual can have on the environment by going green is often negligible. The theory is that if everyone were to go green, it would have a significant and noticeable impact, but not everyone can be convinced to go green and many believe that doing so has no real impact outside of the economics. This makes going green a personal choice for many, which does not necessarily result in concrete economic or environmental benefits (https://www.sapling.com/6182126/d isadvantages-going-green).

\section{Conclusion}

Consumers request for green technology productions is on sharp increase. Besides, government consumers are highly mandated to purchase green where is available, and the spectrum of the products by such provisions is on the rise. As for business customers, if it is illustrate a return on investment in green products, then request will materialize. The greatest opportunities are in commodities which decrease energy consumption. Even so, a growing number of business purchasers can be expected to be motivated by nothing more than the desire to be perceived as supporting environmental sustainability. Thus, change is coming. The green in technology products is being installed in the R\&D phase. Products are being reconfigured to use fewer hazardous substances, require less shipping material, operate on less energy and promote end-of-life recycling. So in terms of environmental sustainability, the technology industries are embracing change. They are changing to avoid negative consequences or to meet green demand or to achieve both. Whatever their motivation, they are incontrovertibly shifting toward green.

\section{References}

Al-Ali, A. R., Imran Zualkernan, and Fadi Aloul. "A mobile GPRS-sensors array for air pollution monitoring." Sensors Journal, IEEE 10.10 (2010): 1666-1671.

Bako-Biro, Zsolt. Human perception, SBS symptoms and performance of office work during exposure to air polluted by building materials and personal computers. Diss. Department for Mechanical Engineering, Technical University of Denmark, 2004. 
Calero, Coral, and Mario Piattini. "Introduction to Green in software engineering." Green in Software Engineering. Springer International Publishing, 2015. 3-27.

(http://www.powerhousegrowers.com/4business-goals-of-green-technology/)

(http://www.wncgbc.org/about/importance-ofgreen-building)

IEA World Energy; Outlook 2007, 2008

IEEE (2014). SWEBOK V3.0. Guide to the Software Engineering Body of Knowledge. Bourque, P. and Fairley, R.E. (eds.), IEEE Computer Society.

Mahmood Zohoori, Samaneh Falaki., "Relationship between Information System Components, Trust, and User Satisfaction in terms of Using Green Processes and Technology" International Journal of Science and Engineering Applications (IJSEA) (Volume 5, Issue 7 September 2016).

Monu Bhardwaj et al. "The Advantages and Disadvantages of
Green Technology" Journal of Basic and Applied Engineering Research, Volume 2, Issue 22; OctoberDecember, 2015: pp. 1957-1960.

Ravali, K., and P. Ashok Kumar. "Techno-Pollution." $\quad$ Computer $\quad 1.4$ (2011): 1416-1420.

(Recent Research in Science and Technology 2014, 6(1): 97-100 ISSN: 2076-5061 Available Online: http://recent-science.com).

Sanjukta Banerjee et al. "Advantages of green technology" Recent Research in Science and Technology 2014, 6(1): 97-100.

Soni, Ghanshyam Das. "ADVANTAGES OF GREEN TECHNOLOGY." Social Issues and Environmental Problems, $\quad$ Vol.3 (Iss.9:SE): Sep, 2015] ISSN- 23500530(O) ISSN- 2394-3629(P).

(https://www.sapling.com/6182126/d isadvantages-going-green).

(www.ajcebeats.com/theimportance-of-green-technology/) 